\title{
PROCESOS COGNITIVOS Y DESEMPEÑO LECTOR
}

\author{
Violeta TAPia M. ${ }^{1}$ Y Jorge LUnA $A .{ }^{2}$ \\ Universidad Nacional Mayor de San Marcos, Perú \\ (RECIBIDO EL 13/12/2007, ACEPTADO EL 05/04/2008)
}

\section{RESUMEN}

Teniendo como marco de referencia la Teoría de la Modificabilidad Cognitiva Estructural de Reuven Feuerstein y la Psicolingüística Textual de W. Kintsch y T.A.van Dijk el presente estudio tuvo como objetivo analizar los procesos mentales en términos de operaciones del pensamiento y funciones cognitivas, así como de los niveles del procesamiento de textos, que diferencian a los alumnos de alto y bajo desempeño lector de segundo a quinto grado de secundaria.

Se realizó un análisis de cada una de las preguntas de un test de lectura estandarizado en Lima, en términos de la demanda cognitiva (operaciones mentales y funciones cognitivas) que plantea su solución. Se organizó y distribuyó los ítems del test por categoría de operaciones y funciones y aspectos del procesamiento del texto, identificándose las operaciones del pensamiento: Clasificación, Análisis-Síntesis, Inferencia lógica y Razonamiento hipotético

La muestra comprendió 258 alumnos de ambos sexos, de segundo a quinto grados de educación secundaria de centros educativos particulares de clase B.

Se emplearon técnicas de procesamiento y análisis cuantitativo y cualitativo de los datos como las siguientes:

1) Análisis de varianza para determinar la significatividad de las diferencias entre los puntajes de las respuestas correctas de los buenos y deficientes lectores en los ítems correspondientes a cada una de las operaciones mentales, por grado de estudio.

2) Determinación de los porcentajes acumulados de las frecuencias de respuestas correctas en los buenos lectores, medio y deficientes lectores por grado de estudio a fin de identificar los niveles de dificultad de los ítemes en cada grado.

3) En base al análisis de los porcentajes acumulados, se distribuyó los ítems difíciles y de dificultad media de los buenos y deficientes lectores por categoría de operación por grado de estudio cuya cantidad fue expresada en términos de porcentaje.

Resumiendo el primer nivel de análisis cuantitativo, se apreció que, si bien existen diferencias significativas entre los puntajes de ciertos ítems de cada categoría de operaciones del pensamiento de los buenos y deficientes lectores, estas diferencias tienden a acentuarse en los últimos grados en las operaciones de Análisis-Síntesis e Inferencia Lógica, manteniéndose

1 Profesora Emérita de la Universidad Nacional Mayor de San Marcos, Lima Perú.

2 Ex profesor Asociado de la Facultad de Psicología de la Universidad Nacional Mayor de San Marcos, Lima Perú. 
la diferencia entre los buenos y deficientes lectores en uno de los ítems de razonamiento hipotético.

En un segundo nivel de análisis cuantitativo y cualitativo más detallado, se intentó explicar las diferencias no sólo en relación a las operaciones y funciones cognitivas sino de las características del procesamiento textual, lo cual permitió apreciar el desempeño diferencial y las dificultades de cada grupo de alumnos.

Palabras clave: Modificabilidad cognitiva estructural, Operaciones del pensamiento, Funciones cognitivas, Procesamiento textual.

\begin{abstract}
This study had the objective to analyze the mental processes in terms of the thinking abilities and the cognitive functions as well as some levels of text processing that distinguish (differentiate) good and poor reader students from High School. The analysis was based on the theories: The Structural Cognitive Modifiability of Reuven Feuerstein and the Text Processing of W. Kintsch and T.A Van Dick.

The cognitive demands of solution from each one of the questions of a standardized reading test were analyzed as mentioned before. The following cognitive processes were identified and organized: Classification, Analysis-Synthesis, Logic inference and Hypothetical reasoning.

The sample was conformed by 258 students (males and females) from second to fifth grades of private high schools, class B, and different techniques of data analysis were applied such as: 1) ANOVA design to determine significant differences between the performance of good and poor readers in items corresponding to each one of the cognitive processes by grade of study; 2) Cumulative percentage of the correct answer frequency of the good, the average and the poor readers by category of abilities and grades.

In a first analysis level, the quantitative results showed significant differences between the scores of some items of each category of thinking abilities between good and poor readers. These differences were increasing in the last grades, in Analysis-Synthesis and Logic Inference. Difficulties in hypothetical reasoning were maintained in all grades in the same test item.

In a more detailed quantitative and qualitative analysis, explanations of the differences were attempted in relation of the thinking abilities and the mental functions as well as the text processing aimed to show the differences in reading achievement and also the difficulties of each group of students.
\end{abstract}

Keywords: Structure cognitive modifiability, Thinking abilities, Cognitive functions, Text processing.

\title{
INTRODUCCIÓN
}

En el marco de las reformas educativas, las concepciones sobre el aprendizaje y la enseñanza ponen énfasis en la responsabilidad del estudiante de construir activamente las elaboraciones mentales que hacen posible el acceso personal al significado de lo que aprenden. Aprender 
de modo eficaz implica que los estudiantes dominen y coordinen adecuadamente diversas habilidades, entre ellas las del pensamiento.

La lectura es una de las habilidades más importantes a desarrollar en los alumnos para que lleguen a ser adultos exitosos y productivos. Hoy más que nunca deviene en un proceso crucial, una época caracterizada por la producción ilimitada de información.

En el marco de la Ciencia Cognitiva y de la Psicolingüística se han desarrollado modelos explicativos cada vez más sistemáticos sobre una caracterización psicológica unitaria de la comprensión lectora, con un interés no sólo teórico sino metodológico que sustente los programas de intervención.

En la actualidad existe ya un consenso en que la lectura es una actividad intelectual compleja y multidimensional que, como parte integral del lenguaje, comporta todas sus características. La lectura es una actividad a través de la cual los lectores construyen significado (comprensión), en el que se combinan los conocimientos y experiencias previas, la competencia lingüística (fonológica, léxica, información sintáctica, semántica), la información aportada por el texto y el contexto y la forma cómo se relacionan con el texto (de acuerdo a la gramática textual). Es por lo tanto, un proceso cognitivo, psicolingüistico y sociocultural.

Como actividad mental guiada por el pensamiento, la lectura implica un sistema de procesos que va más allá de la traducción de símbolos gráficos a modos de lenguaje oral e interpretación de su significado manifiesto o literal que pone en relación a los conceptos, ideas y valores que lo contienen. La comprensión tiene lugar en la transacción entre el lector y el texto. El lector aporta muchas cosas al evento lector, el texto tiene ciertas características y aún el significado emerge sólo del compromiso del lector con el texto en un momento particular.

Como proceso dinámico e interactivo, la lectura involucra un conjunto de operaciones cognitivas a través de las cuales el lector va estableciendo relaciones entre las diferentes ideas (proposiciones derivadas del texto), formando una representación o modelo mental del mismo.

En este proceso de construcción del significado del texto, el lector crea una relación jerárquica entre las ideas, unas más generales que otras, relacionando e integrando la información del texto a las estructuras cognitivas existentes (esquemas), elaborando hipótesis, identificando ideas principales, ejecutando razonamiento hipotético deductivo, realizando inferencias, estableciendo conclusiones, razonamiento analógico, resumiendo y obteniendo una idea global del texto.

Reconociendo la importancia de la aplicación de estrategias para la comprensión lectora, en la medida que a través de ellas se desarrollan las habilidades del pensamiento, surge, sin embargo, una interrogante en relación a las operaciones y funciones del pensamiento que acompañan o subyacen a la aplicación de las estrategias de lectura, generando representaciones que son requeridas (ideas o información almacenadas en la memoria a largo plazo y activadas en la memoria de corto plazo) para asistir al lector en la creación de una serie de conexiones entre las representaciones a que dan lugar el texto y sus diferentes partes: las representaciones y transformaciones mentales que le van dando sentido a lo 
que se lee, monitorear el significado emergente en la medida que el lector lee y usa sus estrategias. Cuanto más información se encuentra, más conexiones se realizan.

El modelo mental que se crea tendría como base las funciones y operaciones y funciones del pensamiento que posibilitan el uso de estrategias cognitivas y metacognitivas para una mejor asimilación de la nueva información a la estructura (esquema) cognitiva del lector.

Uno de los aportes más significativos en el estudio de los procesos en la construcción de los conocimientos lo constituye la Teoría de la Modificabilidad Cognitiva Estructural (TMCE) de Reuven Feuerstein, fundamento de un conjunto de sistemas aplicativos de intervención cognitiva. Para expresar sólo lo esencial y relevante al tema que nos ocupa, la Teoría de la Modificabilidad Cognitiva Estructural es una teoría de la inteligencia definida como la propensión o tendencia del organismo a ser modificado en sus propias estructuras, como respuesta a la necesidad de adaptación a nuevos estímulos sean de origen interno o externo.

Feuerstein y colaboradores han elaborado una taxonomía de operaciones del pensamiento definidas como las acciones interiorizadas, organizadas y coordinadas, por las cuales se elabora la información procedente de fuentes externas e internas. Estas operaciones en términos formales se refieren a las manipulaciones y combinaciones mentales de representaciones internas de carácter simbólico (imágenes, conceptos, palabras, etc.). Las operaciones mentales unidas de modo coherente son organizadas en estructuras de conocimiento y dan como resultado la estructura mental de la persona.

Las estructuras cognitivas como representaciones organizadas de la información almacenada, son dinámicas y modificables y pueden describirse como marcos conceptuales y como esquemas.

Las funciones cognitivas son las unidades mentales o estructuras básicas que sirven de soporte a todas las operaciones mentales para adquirir y procesar información y, en consecuencia, para dar respuesta a las demandas del ambiente. Se agrupan en tres categorías: a) funciones cognitivas de entrada, las cuales son utilizadas en el proceso de búsqueda de información; b) las funciones de elaboración, utilizadas en el procesamiento de la información; c) funciones cognitivas de salida, que son utilizadas para expresar la respuesta o resultado del acto mental.

En los siguientes cuadros se presentan las operaciones y funciones mentales.

\section{OPERACIONES MENTALES}

Razonamiento Lógico

Pensamiento Divergente

Razonamiento Silogístico

Razonamiento Transitivo

Razonamiento Analógico 
Inferencia Lógica

Análisis-Síntesis

Proyección de Relaciones Virtuales

Codificación - Decodificación

Clasificación

Comparación

Transformación mental

Representación mental

Diferenciación

Identificación

\section{FUNCIONES COGNITIVAS}

Fase de Input (Entrada) $\quad$ Fase de Elaboración $\quad$ Fase de Output (Salida)

1. Percepción clara y preci- 1. Percibir el problema y desa.

2. Comportamiento exploratorio sistemático. finirlo con claridad.

2. Facilidad para distinguir datos relevantes e irrelevan3. Uso de vocabulario - con- tes.

ceptos apropiados.

4. Orientación espacial eficiente.

3. Ejercitar la conducta comparativa.

4. Amplitud del campo men-

5. Orientación temporal efi- tal. ciente.

5. Percepción global (no epi-

6. Constatar la constancia y sódica) de la realidad. permanencia del objeto.

7. Recopilación de datos con precisión y exactitud.

8. Considerar dos o más fuentes de información.
6. Uso de razonamiento lógico.

7. Interiorización del propio comportamiento.

8. Pensamiento hipotético inferencial.

9. Aplicación de estrategias de verificación de hipótesis.

10. Conducta planificada.

11. Elaboración de categorías cognitivas.

12. Aplicación de la conducta sumativa.

13. Facilidad para establecer relaciones virtuales.
1. Comunicación descentralizada (no egocéntrica).

2. Proyección de relaciones virtuales.

3. Ausencia de bloqueos al comunicar respuestas.

4. Respuestas certeras y justificadas.

5. Dominio de vocabulario adecuado.

6. Precisión y exactitud al comunicar respuestas.

7. Transporte visual adecuado.

8. Conducta controlada, no impulsiva. 
Algunas observaciones empíricas nos han llevado a considerar el rol que cumplen las operaciones del pensamiento y las funciones mentales como fundamento de las estrategias y plantear la necesidad de identificarlas en el proceso lector. En una experiencia sobre el desarrollo de estrategias cognitivas y metacognitivas de comprensión lectora, Tapia (1996) observó que los alumnos mejoraban la aplicación de las estrategias cuando se trataba de mejorar sus procesos básicos del pensamiento (comparación, clasificación, relaciones espaciales, relaciones temporales) aún cuando no se controló empíricamente.

Desde la perspectiva psicolingüística, junto a los procesos cognitivos subyacentes a la comprensión lectora, es importante conocer los mecanismos y procesos implicados en el procesamiento de los textos que explican la precisión y eficacia de la comprensión de los mismos, y a través de los cuales se activan las habilidades del pensamiento.

Uno de los modelos psicolingüísticos influyentes para la comprensión de un texto es el desarrollado por Teum van Dijk y Walter Kintsch. En su teoría de procesamiento textual distinguen dos niveles de comprensión: el nivel texto base y el nivel modelo de la situación, para la integración de la información del texto (coherencia).

En el primer nivel -texto base- se trata de la interrelación de los significados del texto entre sí, de modo que constituyan un todo coherente en el que cada idea guarde una relación precisa con el resto de las ideas. En este nivel se distinguen tres categorías textuales que corresponden a los conceptos de microestructura, macroestructura y superestructura. El siguiente cuadro presenta un esquema de estas tres categorías textuales: 
Panorámica de los procesos implicados en la construcción del texto-base

\begin{tabular}{cc}
\hline \multicolumn{2}{c}{ Construcción del texto-base } \\
\hline Niveles de la actividad & Resultado \\
\hline
\end{tabular}

A) Microestructura

1. Reconocer palabras escritas Se accede al significado de las palabras o significado lexical.

2. Construir proposiciones

Se organizan los significados de las palabras en ideas elementales o proposiciones.

3. Conectar las proposiciones

Se relacionan las proposiciones entre sí.

\section{B) Macroestructura}

4. Construir la macroestructura
Se derivan del texto y de los conocimientos del lector, las ideas globales que individualizan, dan sentido y diferenciación a las proposiciones derivadas del texto.

\section{C) Superestructura}

5. Interrelacionar globalmente las ideas
Las ideas globales se relacionan entre sí en términos causales, descriptivos, problemasolución, comparativos o secuenciales.

Fuente: Sánchez, Emilio (1999). "El lenguaje escrito: Adquisición e intervención educativa". En: Psicología de la Instrucción I. Madrid: Edit. Síntesis S.A.

El segundo nivel, modelo de la situación, más profundo corresponde a otra forma de integración: la integración de la información del texto con el resto de nuestros conocimientos hasta fundirse con ellos. Lo que retenemos en nuestra mente no sería el texto, sino el mundo o situación que en él se refiere.

Los dos niveles, texto base y modelo de la situación, acentúan los dos ejes de la Psicolingüística actual: texto y contexto. No se puede comprender bien un texto si no se sabe diferenciar los distintos niveles de importancia de las ideas que constituyen el significado de su contenido. Según se desprende del modelo de Van Dijk y Kintsch, la comprensión es multiestructural.

Por las consideraciones expuestas, la interrogante principal que orientó el presente estudio fue: ¿Cómo se diferencian los alumnos de alto y bajo desempeño lector respecto a las operaciones y funciones cognitivas y de los niveles de procesamiento textual?

En consecuencia, el objetivo principal de la investigación, cuyos resultados damos a conocer, fue describir y comparar los procesos mentales en términos de operaciones del pensamiento y funciones cognitivas; y de los niveles del procesamiento de 
textos que diferencian a los alumnos de alto y bajo desempeño lector de segundo a quinto de secundaria.

\section{MÉTODO}

\section{Muestra}

Los sujetos del estudio fueron 258 alumnos de ambos sexos del nivel secundario de segundo, tercer, cuarto y quinto grado de centros educativos particulares de clase B de la ciudad de Lima Metropolitana, elegidos de manera intencional (Cuadro N. ${ }^{\circ} 1$ ).

Cuadro N. ${ }^{0}$ 1. Distribución de la muestra por grado de estudios.

\begin{tabular}{ccc}
\hline Grados & Número & Porcentaje \\
\hline Segundo & 142 & 55 \\
Tercero & 30 & 12 \\
Cuarto & 50 & 19 \\
Quinto & 36 & 14 \\
\hline Total & 258 & 100 \\
\hline
\end{tabular}

\section{Instrumento}

Se utilizó el test de Comprensión de Lectura, diseñado, elaborado y validado por V. Tapia (1982) y estandarizado conjuntamente con M. Silva.

La prueba comprende diez fragmentos de diferente contenido, tanto de humanidades como de carácter científico, seguido cada uno de preguntas o ítems en su mayor parte de selección múltiple con tres distractores y una respuesta correcta; asimismo, presenta una pregunta de completamiento y dos de jerarquización.

La comprensión de la lectura es concebida como una habilidad genérica que se manifiesta a través de un conjunto de subhabilidades medidas mediante preguntas que indagan sobre:

- Información de hechos: habilidad para reconocer la información del texto.

- Definición del significado de las palabras: habilidad para identificar el concepto de los términos de la lectura.

- Identificación de la idea central del texto: habilidad para identificar el tema principal del fragmento.

- Interpretación de hechos: habilidad para identificar el significado de partes del fragmento expresado con proposiciones diferentes.

- Inferencia sobre el autor: habilidad para identificar la intención, el propósito y el punto de vista del autor. 
- Inferencia sobre el contenido del fragmento: habilidad para extraer una conclusión de un párrafo con diferentes proposiciones.

- Rotulación: habilidad para identificar el título apropiado al texto de lectura.

Para los fines del presente estudio, los ítemes se han reclasificado de acuerdo a las categorías de las operaciones del pensamiento.

El texto fue validado mediante el juicio de expertos lo que permitió determinar la validez de contenido: análisis de ítemes, a fin de obtener los índices de dificultad y discriminación de los mismos; la validez empírica, mediante la correlación con el Test de Habilidad Mental de California; y la confiabilidad, a través del test y retest.

La estandarización del test se realizó con 2215 alumnos habiéndose elaborado el Baremo con normas percentilares por grado y sexo para los grados de primero a quinto de secundaria.

\section{Procedimiento}

1. Análisis de cada una de las preguntas del test en términos de la demanda cognitiva (operaciones mentales y funciones cognitivas) que plantea su solución, los aspectos del texto base y del modelo de la situación.

Es importante anotar que frente a la cantidad limitada de ítems en un texto y la demanda cognitiva que plantean, las estrategias de solución dependen de la naturaleza $\mathrm{y}$ contenido del texto y de las preguntas formuladas. Si bien es cierto que una prueba no agota la totalidad de aspectos a evaluar, sí permite dar cuenta de leer de una manera básica.

Como resultado del análisis de las demandas cognitivas de solución de cada uno de los ítems del test, se identificó las siguientes operaciones del pensamiento: clasificación, análisis-síntesis, inferencia lógica y razonamiento hipotético deductivo.

2. Organización de los ítems del test por categorías de procesos cognitivos (operaciones y funciones cognitivas) y aspectos del procesamiento del texto (aspectos del texto base), como se puede observar en el siguiente cuadro: 
Cuadro N. ${ }^{\circ}$ 2. Distribución de los ítems del test de lectura por categorías de procesos cognitivos (operaciones del pensamiento y funciones cognitivas) y en relación a los aspectos del procesamiento del texto base.

\begin{tabular}{|c|c|c|c|c|}
\hline Operaciones & Funciones & Fragmento & Ítem & $\begin{array}{l}\text { Aspectos del texto base (microestructura, macroestruc- } \\
\text { tura y superestructura) }\end{array}$ \\
\hline \multirow{10}{*}{ Clasificación } & Orientación espacial & 1 & 1 & \multirow{2}{*}{$\begin{array}{l}\text { Microestructura: significado de palabras. } \\
\text { Ídem. }\end{array}$} \\
\hline & $\begin{array}{l}\text { Vocabulario. Comportamiento Siste- } \\
\text { mático. }\end{array}$ & 1 & 2 & \\
\hline & Vocabulario. Comportamiento & 2 & 5 & \multirow{2}{*}{$\begin{array}{l}\text { Microestructura: significado de palabras en proposiciones. } \\
\text { Microestructura: Identificación de idea explícita. }\end{array}$} \\
\hline & Sistemático. Precisión y exactitud & & & \\
\hline & Ídem, comparación espontánea & 4 & 13 & Microestructura: significado de proposiciones. \\
\hline & Ídem & 4 & 15 & Superestructura: estructura del contenido del texto \\
\hline & Ídem & 6 & 20 & $\begin{array}{l}\text { Macroestructura: Derivada del significado global del texto. } \\
\text { Superestructura: Organización del contenido. }\end{array}$ \\
\hline & $\begin{array}{l}\text { Ídem. Orientación espacial. Percepción } \\
\text { global, no episódica }\end{array}$ & 7 & 24 & Microestructura: Idea explicita en proposiciones. \\
\hline & Ídem. Dos o más fuentes de información & 8 & 27 & $\begin{array}{l}\text { Macroestructura: derivada de la idea global del texto. } \\
\text { Superestructura: organización del contenido. }\end{array}$ \\
\hline & Ídem. & 8 & 30 & $\begin{array}{l}\text { Macroestructura: Idea global del texto. Superestructura: or- } \\
\text { ganización del contenido; conocimientos previos. }\end{array}$ \\
\hline \multirow{14}{*}{$\begin{array}{l}\text { Análisis- } \\
\text { Síntesis }\end{array}$} & $\begin{array}{l}\text { Relación de dos o más fuentes de in- } \\
\text { formación. Comportamiento } \\
\text { Sistemático. Comportamiento no epi- } \\
\text { sódico. Conducta sumativa }\end{array}$ & 1 & 3 & $\begin{array}{l}\text { Microestructura: Ideas globales derivadas de los párrafos y } \\
\text { relaciones de orden. }\end{array}$ \\
\hline & Ídem. Relaciones temporales & 1 & 4 & \multirow{13}{*}{$\begin{array}{l}\text { Ídem. } \\
\text { Microestructura: Idea global de párrafo. } \\
\text { Microestructura: Idea global de párafo y relación de orden. } \\
\text { Macroestructura: Idea global derivada del texto. } \\
\text { Ídem } \\
\text { Ídem } \\
\text { Ídem } \\
\text { Ídem } \\
\text { Idem } \\
\text { Ídem } \\
\text { Ídem } \\
\text { Ídem } \\
\text { Ídem } \\
\text { Ídem } \\
\text { Ídem }\end{array}$} \\
\hline & Ídem & 2 & 6 & \\
\hline & Ídem. Orientación temporal & 2 & 7 & \\
\hline & Ídem & 2 & 8 & \\
\hline & Ídem. Orientación espacial & 3 & 9 & \\
\hline & Ídem Relaciones temporales & 3 & 11 & \\
\hline & Ídem. Conducta comparativa & 4 & 14 & \\
\hline & Ídem. Conducta comparativa & 6 & 21 & \\
\hline & Ídem. Conducta comparativa & 6 & 22 & \\
\hline & Ídem. & 6 & 23 & \\
\hline & Ídem. Comportamiento descentralizado & 7 & 26 & \\
\hline & Ídem. Instrumentos verbales Precisión & 8 & 28 & \\
\hline & y exactitud & 9 & 33 & \\
\hline \multirow{13}{*}{$\begin{array}{l}\text { Inferencia } \\
\text { lógica }\end{array}$} & Relaciones temporales. Conducta su- & 3 & 10 & \multirow{2}{*}{$\begin{array}{l}\text { Macroestructura: Idea global derivada del texto. } \\
\text { Ídem }\end{array}$} \\
\hline & mativa. Conducta no episódica.Dos o & 3 & 12 & \\
\hline & más fuentes de información. Compor- & 5 & 16 & Ídem \\
\hline & tamiento sistemático (reflexivo). & 5 & 19 & Ídem \\
\hline & Precisión en recoger los datos & 7 & 25 & Ídem. Conocimientos previos \\
\hline & Ídem & 8 & 29 & Ídem “ “ \\
\hline & Ídem & 9 & 31 & Ídem \\
\hline & Ídem & 9 & 32 & Ídem \\
\hline & Ídem & 9 & 34 & Ídem \\
\hline & Ídem & 10 & 36 & Ídem \\
\hline & Ídem & 10 & 37 & Ídem \\
\hline & Ídem & 10 & 38 & \\
\hline & Ídem & & & \\
\hline Razonamiento & $\begin{array}{l}\text { Vocabulario. Definición clara y preci- } \\
\text { sa. Dos o más fuentes de información, }\end{array}$ & 3 & 17 & \multirow{3}{*}{$\begin{array}{l}\text { Macroestructura: Derivada de la idea global del texto a tra- } \\
\text { vés de relaciones entre las microestructuras. } \\
\text { Macroestructura: Derivada de la idea global del texto. } \\
\text { Ídem }\end{array}$} \\
\hline $\begin{array}{l}\text { nipotetico } \\
\text { deductivo }\end{array}$ & comunicación descentralizada & 5 & 18 & \\
\hline & & 10 & 35 & \\
\hline
\end{tabular}


Aspecto del texto base: Superestructura (representación articulada en un sistema retórico). Las ideas globales se relacionan entre sí en términos narrativos, descriptivos, causales, problema/ solución, comparativos, argumentativos.

Para el análisis de la estructura retórica de los fragmentos del test, se ha tomado como referencia la clasificación expuesta en: Vidal, J.G y Manjón D.G. (2000), Dificultades de Aprendizaje e intervención psicopedagógica. Volumen 2: Lectura y Escritura.

Fragmento 1: Expositivo: Descriptivo y secuencial (característica del contenido temático: Desarrollo ambiental).

Fragmento 2: Expositivo: Esquema funcional de orden temporal (característica del contenido temático: Tecnológico).

Fragmento 3: Expositivo: Descriptivo (característica del contenido temático: literario).

Fragmento 4: Expositivo: Descriptivo (característica del contenido temático: Ciencias Naturales).

Fragmento 5: Expositivo: Descriptivo (característica del contenido temático: Ciencias Naturales).

Fragmento 6: Expositivo: Esquema ilustrativo (característica del contenido temático: Ciencias Sociales).

Fragmento 7: Expositivo: División y clasificación (característica del contenido temático: Ciencias Naturales).

Fragmento 8: Expositivo: Descriptivo (característica del contenido del texto: Ciencias Naturales).

Fragmento 9: Expositivo: Descriptivo (característica del contenido del texto: Ciencias Sociales - histórico).

Fragmento 10: Expositivo: Descriptivo (Característica del contenido del texto: Ciencias Sociales* histórico).

\section{Operaciones cognitivas}

\section{Clasificación}

A partir de categorías, reunimos grupos de elementos, de acuerdo a atributos definitorios. A través de la clasificación, nos movemos de relaciones establecidas entre diversos elementos simples a la proyección de relaciones entre conceptos más extensos.

Leonardo Higueras (1998) condensa en la siguiente cita el significado de la clasificación: "clasificar es distribuir y agrupar cosas según ciertos principios, con lo que obtenemos una serie de grupos o categorías". 
La clasificación puede considerarse como una extensión de la comparación; cuando se encuentran suficientes analogías, es posible formar un grupo que tenga características distinguibles de otros grupos los que a su vez, presentan conjuntos distintos de semejanza. Los grupos pueden ser también comparados e incluidos en sistemas mayores aún, que es lo que esencialmente sucede en el proceso taxonómico".

La capacidad para clasificar o hacer equivalentes elementos, cosas y sucesos que se perciben como diferentes hace posible que el hombre pueda adaptarse a su entorno, agrupando objetos y acontecimientos en clases para responder a ellos en términos de su pertenencia de clase, antes que en términos de su unicidad.

En el procesamiento de un texto de lectura, la operación de clasificación está vinculada principalmente con el nivel de microestructura a través de las microproposiciones que representan las oraciones y párrafos relacionados con la coherencia local. Se accede al significado de las palabras o significado lexical, considerando que lo que retenemos no son las palabras tal cuales, sino las ideas que con ellas hemos construido el significado: ideas o proposiciones que pueden expresarse, si llegara el caso, con otras palabras

Respecto a las demandas de solución, unas preguntas indagan sobre el significado de palabras $(1,2,5,27)$, otras, sobre categorización $(13,15,20,24,30)$.

Las funciones cognitivas básicamente requeridas son:

- Nivel de entrada: Uso de vocabulario y conceptos apropiados, comportamiento sistemático, claridad y precisión, orientación espacial.

- Nivel de elaboración: Facilidad para distinguir datos relevantes e irrelevantes, conducta comparativa espontánea, elaboración de categorías cognitivas.

- Nivel de salida: Expresión (sin bloqueo) en la comunicación de respuestas, uso de instrumentos verbales adecuados, precisión y exactitud en la comunicación de respuestas.

\section{Análisis-Síntesis}

Análisis significa descomponer un todo en sus elementos constitutivos y relacionarlos para elaborar significados o extraer inferencias (síntesis).

En este proceso de construcción del significado se van identificando las ideas principales que expresan la esencia de lo que el autor desea transmitir.

Una lectura se compone de varios párrafos. Si reunimos las ideas principales de cada uno de ellos, tenemos el resumen de la lectura que recoge el significado esencial (principal del texto).Todas las ideas se integran en una idea o estructura general que proporciona un sentido y coherencia global, correspondiendo este nivel de coherencia a la macroestructura que es el conjunto de las ideas principales del texto jerarquizadas y que funciona como modelo-resumen del texto (González, 2001).

El resumen puede tener distintos niveles de generalidad o de abstracción. El resumen más sucinto, abstracto y general de una lectura es su título. Otros niveles de generalidad 
se relacionan con las ideas principales de los párrafos (microestructuras) y del texto (macroestructura).

La macroestructura del texto que se forja el lector cuando lee, constituye, por lo tanto, el marco global o contexto general que da sentido a los detalles y posibilita la comprensión del contenido; esta macroestructura se forma interrelacionando las ideas del texto. La identificación de las ideas principales está en la base de la comprensión.

Las ideas principales (conceptos globales) las obtenemos fusionando conceptos y deduciendo la idea común general a todos ellos. Si reunimos estas ideas principales, el resultado es un resumen de la lectura (Burón, 1999).

Las preguntas del test identificadas como síntesis son aquellas que indagan sobre el título del párrafo o texto $(3,8,11,26,33)$; la secuencia de las ideas principales en el texto (4, 7); la idea principal derivada del texto $(6,9,14,21,22,23,28)$.

Las funciones del acto mental subyacentes, básicas a las demandas de solución de las preguntas, se relacionan con:

- Nivel de entrada: Comportamiento sistemático, relación de dos o más fuentes de información, relaciones temporales, orientación espacial.

- Nivel de elaboración: Comportamiento no episódico, conducta comparativa espontánea, conducta planificada, conducta sistemática.

- $\quad$ Nivel de salida: Comunicación descentralizada, respuesta certera, precisión y exactitud en las respuestas.

\section{Inferencia lógica}

Esta actividad constituye un proceso clave en la construcción del significado. Es entendida como la capacidad de obtener información o establecer conclusiones que no están expresadas de manera explícita en el texto o en la situación comunicativa: se comprende algún aspecto determinado del texto a partir del significado del resto. Implica ir más allá de la comprensión literal o de la información superficial del texto.

La lectura inferencial supone una comprensión global de la situación comunicativa y de los significados del texto, el reconocimiento de relaciones entre sus partes y de la intención comunicativa que subyace en él. Asimismo, cuando se predice lo que viene a continuación también se está realizando una inferencia a partir de la información disponible en el texto.

También se ponen en juego los saberes previos y la posibilidad de identificar el tipo de texto: narrativo, expositivo, argumentativo, etc.

Goodman (1982), en relación a este proceso, expresa: "La inferencia es un medio poderoso por el cual las personas complementan la información disponible, utilizando el conocimiento conceptual, lingüístico y los esquemas que ya poseen. Los lectores utilizan estrategias de inferencia para encontrar lo que no está explícito en el texto. Pero también infieren cosas que se harán explícitas más adelante. La inferencia es utilizada para decidir sobre 
el antecedente de un pronombre, sobre la relación entre caracteres, sobre las preferencias del autor, entre muchas cosas. Incluso puede utilizarse la inferencia para decidir lo que el texto debería decir cuando hay un error de imprenta”.

Esta habilidad del pensamiento es utilizada en todos los niveles del procesamiento del texto: construcción del texto base (microestructura, macroestructura y superestructura) y el modelo de la situación.

Las preguntas del test cuyas respuestas corresponden, principalmente, a una inferencia se derivan de la estructura global del significado o macroestructura $(10,16,19,25)$ influyendo en gran medida la estructura global que organiza el contenido del texto o superestructura y los conocimientos previos del lector $(29,31,32,34,36,37,38)$.

Las funciones mentales principales subyacentes predominantes son:

- Nivel de entrada: Uso de vocabulario y conceptos apropiados Comportamiento exploratorio, sistemático, recopilación de datos con precisión y exactitud, uso de varias fuentes de información.

- Nivel de elaboración: percibir el problema y definirlo con claridad, facilidad para distinguir datos relevantes e irrelevantes, conducta comparativa espontánea, conducta sumativa, ejercitación de razonamiento hipotético, ejercicio del pensamiento hipotético inferencial.

- Nivel de salida: Expresión (sin bloqueo) en la comunicación de respuestas, uso de instrumentos verbales adecuados, precisión y exactitud en la comunicación de respuestas.

\section{Razonamiento hipotético}

La lectura es un proceso en el que constantemente se formulan hipótesis, que son enunciados que se proponen como posible solución de un problema o como posible explicación de un hecho. Implica la necesidad de comprobarlas para aceptarlas o rechazarlas. Permite realizar inferencias y predicciones de hechos a partir de los ya conocidos y las leyes que los gobiernan.

Las preguntas planteadas en el texto que parten de supuestos para ser verificados a través del razonamiento hipotético son: 17, 18 y 35 derivadas de las ideas globales del texto, y en las que el conocimiento que posee el sujeto influye en gran medida en las respuestas.

Es importante señalar que, aún cuando para responder las preguntas de inferencia está implícito el proceso de razonamiento hipotético para llegar a una conclusión, las preguntas que corresponden a esta operación mental plantean esta demanda cognitiva ya desde su formulación. La pregunta está formulada en términos de hipótesis.

Las funciones requeridas para operar con éxito son:

- Nivel de entrada: Percepción clara y precisa, uso de vocabulario-concepto apropiado, recopilación de datos con precisión y exactitud, uso de dos o más fuentes de información. 
- $\quad$ Nivel de elaboración: Percibir un problema y definirlo con claridad, facilidad para distinguir datos relevantes e irrelevantes, conducta comparativa espontánea, conducta sumativa, elaboración de categorías cognitivas, ejercitación del razonamiento hipotético inferencial.

- Nivel de salida: Comunicación descentralizada, no egocéntrica, proyección de relaciones virtuales, expresión (sin bloqueo) en la comunicación de respuestas, uso de instrumentos verbales adecuados, precisión y exactitud en la comunicación de las respuestas.

2. Evaluación e identificación de los estudiantes en los niveles inferior, medio y superior del desempeño lector de acuerdo a los baremos del test de lectura, por grado de estudios.

\section{Técnicas de procesamiento y análisis cuantitativo y cualitativo de los resultados}

1. Análisis de varianza para determinar la significatividad de las diferencias entre los puntajes de las respuestas correctas de los buenos y deficientes lectores en los ítemes correspondientes a cada una de las operaciones mentales, por grado de estudio

2. Determinación de los porcentajes acumulados de la frecuencia de respuestas correctas en los buenos lectores, lectores medio y deficientes lectores, por grado de estudio a fin de identificar los niveles de dificultad de los ítems (fáciles, dificultad media y difíciles) para cada grupo.

3. En base al análisis de los porcentajes acumulados, se distribuyeron los ítemes difíciles y de dificultad media de los buenos y deficientes lectores por categoría de operación mental, por grado de estudio cuya cantidad fue expresada en términos de porcentajes.

Este procedimiento permitió realizar, además de un análisis cuantitativo, una interpretación cualitativa más detallada de los resultados.

\section{RESULTADOS}

Para el análisis e interpretación de los resultados que permitan responder a los objetivos del presente estudio, se han organizado los datos en dos niveles de información, cuantitativa y cualitativa, los que se presentan a continuación:

1. Análisis de las diferencias significativas entre los puntajes obtenidos por los buenos y deficientes lectores en los ítemes correspondientes a cada una las de las categorías de pensamiento.

Los valores se presentan en la Tabla $\mathrm{N} .{ }^{0} 1$, donde podemos apreciar que existen diferencias significativas entre los puntajes obtenidos por los buenos y deficientes lectores en todas las categorías de operaciones del pensamiento en cada uno de los grados de estudio. Asimismo, se observan resultados diferenciales en cada una de las operaciones en relación a los grados de estudio, que a continuación se detallan: 


\section{Operación de clasificación}

Existen diferencias significativas entre los puntajes de las preguntas 1, 5,13,15, 20, 24 obtenidos por los buenos y deficientes lectores en el segundo grado y sólo en la pregunta 20 en tercer grado; en las preguntas 1, 15, 20 y 30 en cuarto grado; y en la pregunta 24 en quinto grado.

De acuerdo a estos resultados podemos deducir que:

i. Los buenos lectores responden diferencialmente en estos ítemes tanto en segundo y cuarto grado, mejorando los deficientes lectores en quinto grado ya que las diferencias entre los puntajes de los buenos y deficientes lectores no son significativas.

ii. Los alumnos deficientes lectores en el quinto grado, mejoran en esta operación mental. 
Violeta Tapia M. \& Jorge LUnA A.

Tabla N. ${ }^{0} 1$. Nivel de significación de las diferencias entre los puntajes de los buenos y deficientes lectores por grado.

\begin{tabular}{|c|c|c|c|c|c|c|c|c|c|}
\hline & & \multicolumn{2}{|c|}{ SEGUNDO } & \multicolumn{2}{|c|}{ TERCERO } & \multicolumn{2}{|c|}{ CUARTO } & \multicolumn{2}{|c|}{ QUINTO } \\
\hline & Items & F & Sig. & $\mathrm{F}$ & Sig. & F & Sig. & F & Sig. \\
\hline C & 1 & 6,96172 & $0,00935^{*}$ & 0,25490 & 0,62209 & 5,04082 & $0,03348^{*}$ & 1,08233 & 0,30948 \\
\hline $\mathbf{L}$ & 2 & 0,66292 & 0,41703 & \multicolumn{2}{|c|}{ respondieron todos } & 0,46429 & 0,50165 & \multicolumn{2}{|c|}{ respondieron todos } \\
\hline $\mathbf{A}$ & 5 & 6,42128 & $0,01247^{*}$ & 0,14943 & 0,70534 & 1,82460 & 0,18841 & 0,71739 & 0,40612 \\
\hline $\mathbf{S}$ & 13 & 9,21043 & $0,00291 *$ & 0,11712 & 0,73765 & 0,00203 & 0,96443 & 0,30183 & 0,58827 \\
\hline I & 15 & 20,99787 & 0,00001* & 0,14943 & 0,70534 & 6,40525 & $0,017768^{*}$ & 0,01545 & 0,90221 \\
\hline $\mathbf{F}$ & 20 & 8,72746 & $0,00373^{*}$ & 6,50000 & $0,02421^{*}$ & 7,69070 & $0,010130^{*}$ & 0,30183 & 0,58827 \\
\hline $\mathbf{I}$ & 24 & 19,18895 & $0,000024^{*}$ & 1,18182 & 0,29673 & 8,02551 & $0,00879 *$ & 7,12999 & $0,013981^{*}$ \\
\hline \multirow[t]{2}{*}{ C } & 27 & 3,49890 & 0,06368 & 2,47619 & 0,13960 & 0,80270 & 0,37851 & 3,03120 & 0,09565 \\
\hline & 30 & 3,04866 & 0,08318 & \multicolumn{2}{|c|}{ no respondieron } & 6,07792 & $0,020607^{*}$ & 1,36982 & 0,25437 \\
\hline $\mathbf{A}$ & 3 & 11,01023 & $0,00118^{*}$ & 1,18182 & 0,29673 & 1,61491 & 0,21506 & 1,36982 & 0,25437 \\
\hline $\mathbf{N}$ & 4 & 18,20779 & $0,00004^{*}$ & 5,15873 & $0,04077^{*}$ & 44,5714 & $0,000001^{*}$ & 27,8368 & $0,000027^{*}$ \\
\hline $\mathbf{A}$ & 6 & 3,29519 & 0,07181 & 1,18182 & 0,29673 & 0,03044 & 0,86284 & 4,16237 & 0,05351* \\
\hline \multirow[t]{2}{*}{$\mathbf{L}$} & 7 & 1,25429 & 0,26482 & 0,00000 & 1,00000 & 2,33351 & 0,13869 & 0,23404 & 0,63332 \\
\hline & 8 & 3,54056 & 0,06214 & 0,61905 & 0,44551 & 0,00800 & 0,92939 & 0,30183 & 0,58827 \\
\hline$S$ & 9 & 7,65949 & $0,00648^{*}$ & 6,50000 & $0,02421 *$ & 4,55352 & 0,04245 & 4,89338 & $0,037647^{*}$ \\
\hline I & 11 & 2,68781 & 0,10356 & 0,13131 & 0,72290 & 1,97986 & 0,17125 & 12,8333 & $0,00166^{*}$ \\
\hline $\mathbf{N}$ & 14 & 4,14528 & $0,0438^{*}$ & 0,00000 & 1,00000 & 2,76309 & 0,10847 & 0,47312 & 0,49874 \\
\hline $\mathbf{T}$ & 21 & 33,02508 & 0,000001* & 2,16667 & 0,16482 & 0,64935 & 0,42765 & 11,6111 & $0,0025256^{*}$ \\
\hline $\mathbf{E}$ & 22 & 0,00819 & 0,92802 & 5,15873 & $0,04077^{*}$ & 1,44263 & 0,24054 & 0,11640 & 0,73621 \\
\hline $\mathbf{S}$ & 23 & 16,35836 & $0,000089^{*}$ & 39,0000 & 0,00003 & 1,44444 & 0,24025 & 17,1875 & $0,000423^{*}$ \\
\hline $\mathbf{I}$ & 26 & 1,30285 & 0,25581 & 0,00000 & 1,00000 & 1,97986 & 0,17125 & 0,30183 & 0,58827 \\
\hline \multirow[t]{2}{*}{$\mathbf{S}$} & 28 & 13,52073 & 0,00035 & 10,1111 & $0,00724^{*}$ & 7,69070 & 0,01013* & 16,2317 & $0,000562^{*}$ \\
\hline & 33 & 2,85543 & 0,09348 & 13,0000 & $0,00319 *$ & 1,59566 & 0,21773 & 0,23802 & 0,63047 \\
\hline I & 10 & 35,85487 & $0,000001 *$ & 0,48148 & 0,49996 & 0,29572 & 0,59121 & 0,85938 & 0,36397 \\
\hline $\mathbf{N}$ & 12 & 16,15943 & $0,000098^{*}$ & 0,14943 & 0,70534 & 0,05078 & 0,82347 & 4,56780 & $0,043944^{*}$ \\
\hline $\mathbf{F}$ & 16 & 3,11852 & 0,07977 & 0,13131 & 0,72290 & 0,13757 & 0,71372 & 7,12999 & $0,0139812^{*}$ \\
\hline $\mathbf{E}$ & 19 & 1,85420 & 0,17567 & 4,33333 & $0,05769^{*}$ & 4,45205 & $0,04464^{*}$ & 0,07964 & 0,78042 \\
\hline \multirow[t]{2}{*}{$\mathbf{R}$} & 25 & 39,47051 & $0,000001 *$ & 1,18182 & 0,29673 & 3,51343 & 0,07215 & 5,59683 & $0,027223^{*}$ \\
\hline & 29 & 43,78584 & $0,0000001 *$ & 4,33333 & $0,05769^{*}$ & 4,55352 & $0,04245^{*}$ & 69,6667 & $0.000001^{*}$ \\
\hline $\mathbf{L}$ & 31 & 10,34928 & $0,00164^{*}$ & 4,33333 & $0,05769^{*}$ & 3,20197 & 0,08521 & 0,00662 & 0,93590 \\
\hline o & 32 & 3,88891 & 0,05075 & 2,16667 & 0,16482 & 6,40525 & $0,017768^{*}$ & 7,12999 & $0,013981^{*}$ \\
\hline G & 34 & 10,01945 & $0,00193^{*}$ & 34,6667 & $0,000053^{*}$ & 2,29844 & 0,14157 & 0,33387 & 0,56926 \\
\hline I & 36 & 2,62343 & 0,10774 & 0,61905 & 0,44551 & 0,24557 & 0,62437 & 3,33333 & 0,08149 \\
\hline C & 37 & 3,04866 & 0,08318 & 5,15873 & 0,040771* & 0,01951 & 0,89000 & 3,03120 & 0,09565 \\
\hline A & 38 & 1,46487 & 0,22837 & 2,16667 & 0,16482 & 2,98469 & 0,09592 & 0,53922 & 0,47051 \\
\hline H & 17 & 0,90919 & 0,34211 & 1,18182 & 0,29673 & 0,41537 & 0,52490 & 0,47312 & 0,49874 \\
\hline $\mathbf{I}$ & 18 & 7,40186 & $0,00741^{*}$ & 6,50000 & $0,02421 *$ & 1,44263 & 0,24054 & 17,1875 & $0,0004226^{*}$ \\
\hline \multirow[t]{3}{*}{$\mathbf{P}$} & 35 & 0,18260 & 0,66986 & 2,47619 & 0,13960 & 2,33351 & 0,13869 & 0,00662 & 0,93590 \\
\hline & & \multicolumn{2}{|c|}{$* \mathrm{~F}=3,92 \quad 5 \%$} & \multicolumn{2}{|c|}{$* \mathrm{~F}=4,60 \quad 5 \%$} & \multicolumn{2}{|c|}{$* \mathrm{~F}=4,20 \quad 5 \%$} & \multicolumn{2}{|c|}{$* \mathrm{~F}=4,26 \quad 5 \%$} \\
\hline & & \multicolumn{2}{|c|}{$\mathrm{F}=6,84 \quad 1 \%$} & \multicolumn{2}{|c|}{$\mathrm{F}=8,86 \quad 1 \%$} & \multicolumn{2}{|c|}{$\mathrm{F}=7,64 \quad 1 \%$} & \multicolumn{2}{|c|}{$\mathrm{F}=7,82 \quad 1 \%$} \\
\hline
\end{tabular}




\section{Operaciones de análisis - síntesis}

Existen diferencias significativas entre los puntajes de las preguntas 4, 9, 28 de los buenos y deficientes lectores en todos los años, existiendo mayor cantidad de ítemes con estas diferencias en los grados segundo, cuarto y quinto, y menor cantidad de ítemes en tercero.

De acuerdo a estos resultados, podemos aseverar que:

1. Los buenos lectores responden diferencialmente mejor que los lectores deficientes en esta operación mental.

2. En los ítemes 4, 9, 28, las diferencias se mantienen durante todos los grados, evidenciándose que los lectores deficientes no mejoran a través de los años de estudio.

3. Los buenos lectores llegan a mejorar en esta operación en el transcurso de los años de estudio, manteniéndose esta diferencia con respecto a los lectores deficientes.

\section{Operación de inferencia lógica}

Existen diferencias significativas entre los puntajes de las preguntas 10, 12, 25, 29, 31, 32, 34 en segundo grado; de las preguntas 19, 29, 31, 34 y 37 en tercer grado; de las preguntas 19,29 y 32 en cuarto grado; en las preguntas $12,16,25,29$ y 32 en quinto año.

De acuerdo a estos resultados, se evidencia que:

1. Los buenos lectores responden diferencialmente mejor que los lectores deficientes en esta operación

2. Los buenos lectores responden mejor que los deficientes lectores, en el ítemes 29 en todos los grados.

3. Los buenos lectores mejoran a través de los años, sin embargo los lectores deficientes no mejoran.

\section{Operación razonamiento hipotético}

Existen diferencias significativas entre los puntajes de la pregunta 18 en segundo, tercero y quinto año.

No existen diferencias significativas en ningún grado en las preguntas 17 y 35 . De acuerdo a estos resultados, se evidencia que:

1. Teniendo en cuenta que no existe diferencias significativas en dos preguntas, puede ser que la frecuencia de respuesta correcta sea alta o sea baja tanto para los buenos como para los deficientes lectores.

2. Los alumnos buenos y deficientes lectores no mejoran en esta operación a través de los años de estudio. 
Resumiendo, en este primer nivel de análisis cuantitativo, hemos apreciado que si bien existen diferencias significativas entre los puntajes de ciertos ítemes de cada categoría de operaciones del pensamiento de los buenos y deficientes lectores, estas diferencias tienden a acentuarse en los últimos grados en las operaciones de Análisis - Síntesis e Inferencia Lógica, manteniéndose la diferencia entre los buenos y deficientes lectores en uno de los ítemes de razonamiento hipotético.

Estos hallazgos nos plantearon la necesidad de realizar un análisis más detallado a nivel cuantitativo del comportamiento de los ítemes en cada nivel de desempeño; es decir, identificar el nivel de dificultad (muy difícil, dificultad media y difíciles) de los ítemes en los alumnos buenos y deficientes lectores; a nivel cualitativo, intentar explicar las diferencias no sólo en relación a las operaciones y funciones cognitivas sino de las características del procesamiento textual implicadas en las preguntas del test. Es con este fin que presentamos los siguientes resultados:

2. Porcentaje acumulado de la frecuencia de la respuesta correcta de los ítems de los alumnos buenos lectores, lectores medio y deficientes lectores por grado de estudios, con respecto a los baremos de la prueba, los que se muestran en las tablas $\mathrm{N}^{\circ}{ }^{\circ} 2,3,4$ y 5.

En las tablas aparecen los ítemes ordenados por nivel de dificultad (difíciles, dificultad media y fáciles) determinado por el porcentaje de la frecuencia acumulada de las respuestas acertadas de menor a mayor, en cada grado de la muestra. El orden de dificultad de los ítemes se estableció de acuerdo a tercios del total de la muestra considerándose de 0 a $33 \%$ como difícil, de 34 a $66 \%$ de dificultad media y de 67 a 100\% como fácil. 
PROCESOS COGNITIVOS Y DESEMPEÑO LECTOR

Tabla N. ${ }^{\circ}$ 2. Porcentaje acumulado de la frecuencia de las respuestas correctas de los ítems de los alumnos buenos lectores, lectores medio y deficientes lectores.

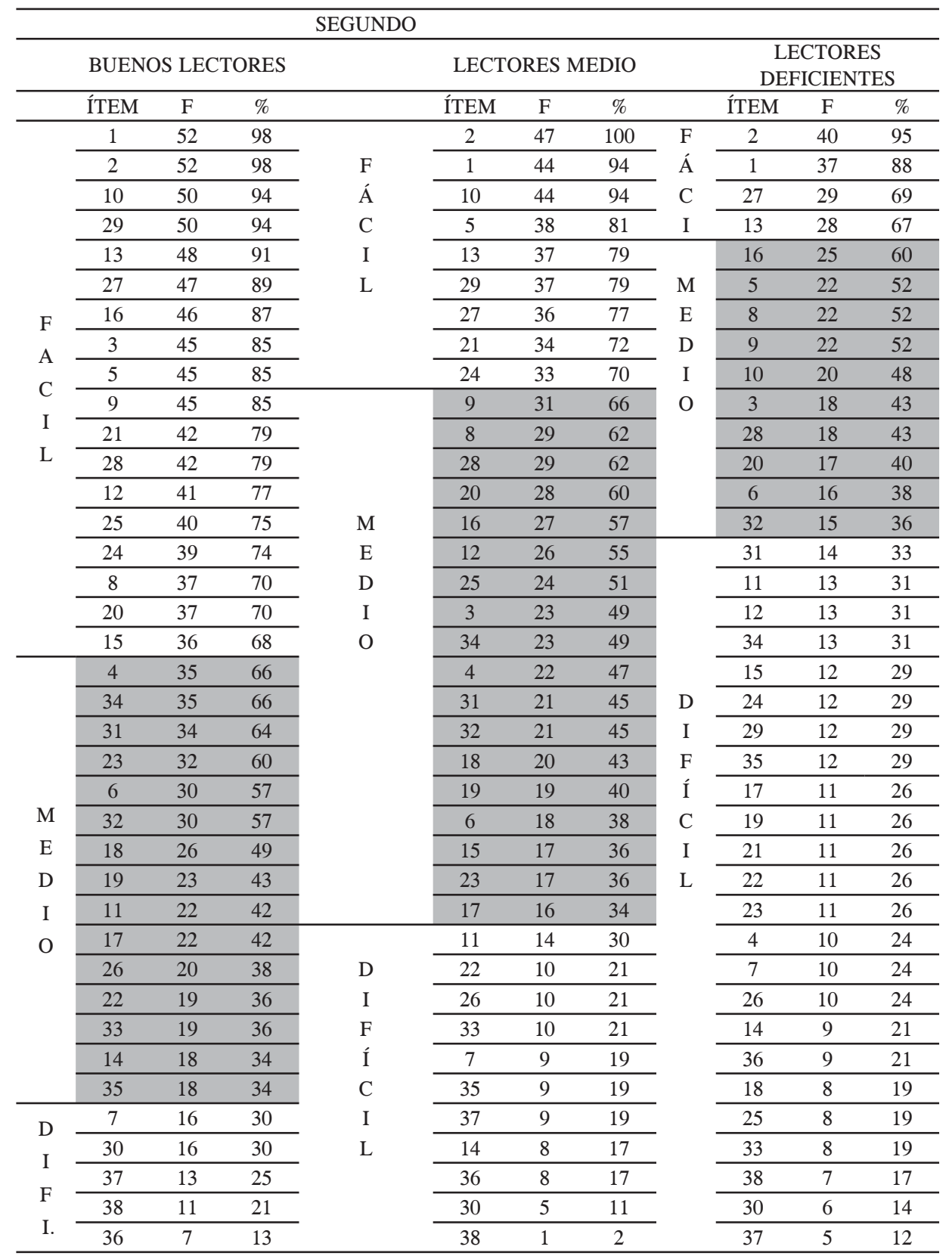


Violeta Tapia M. \& Jorge Luna A.

Tabla N. ${ }^{\circ}$ 3. Porcentaje acumulado de las respuestas correctas de los ítemes de los buenos lectores, lectores medio y deficientes lectores.

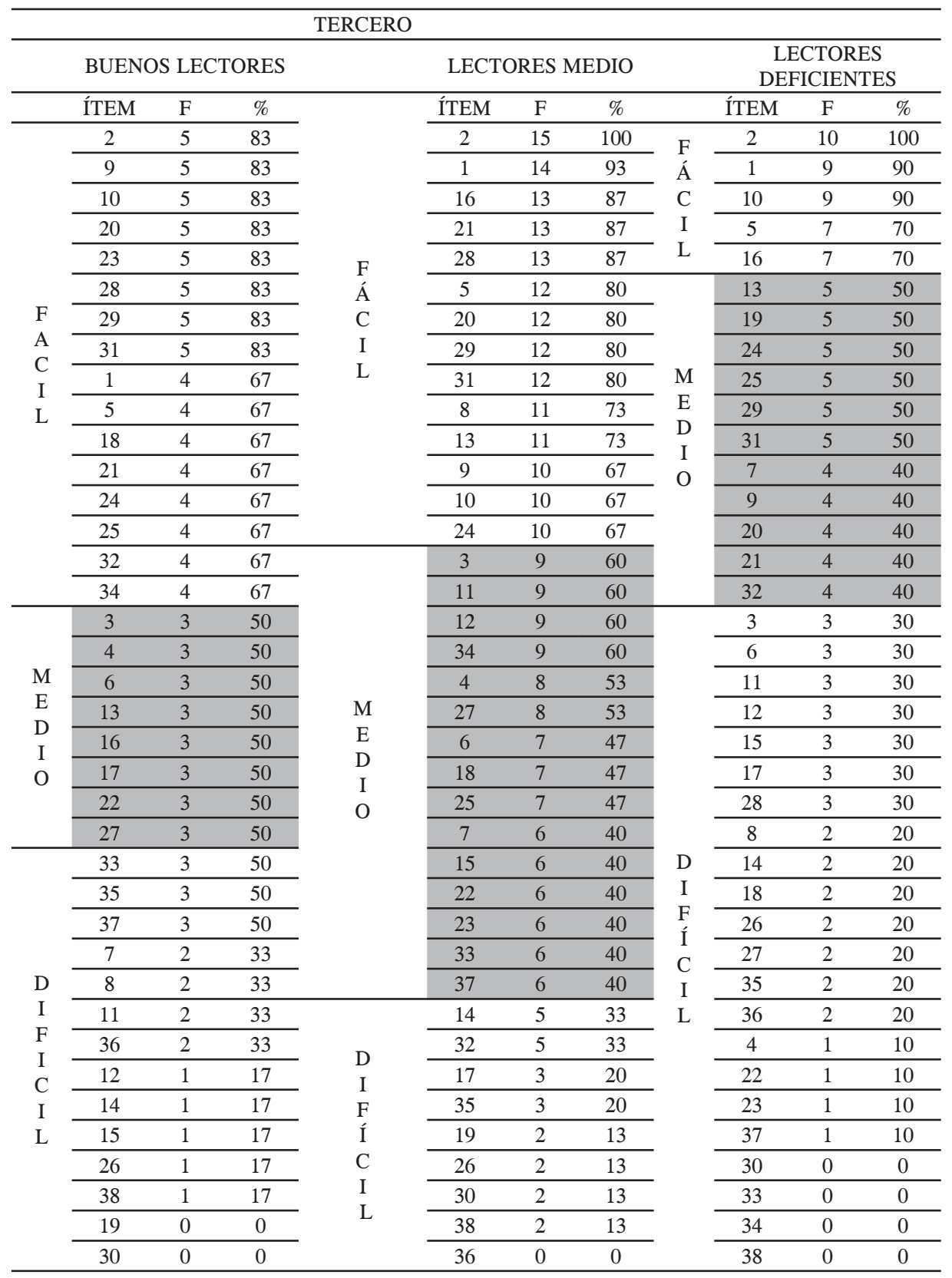


PROCESOS COGNITIVOS Y DESEMPEÑ LECTOR

Tabla N. ${ }^{\circ}$ 4. Porcentaje acumulado de las respuestas correctas de los ítemes de los alumnos buenos lectores, lectores medio y deficientes lectores.

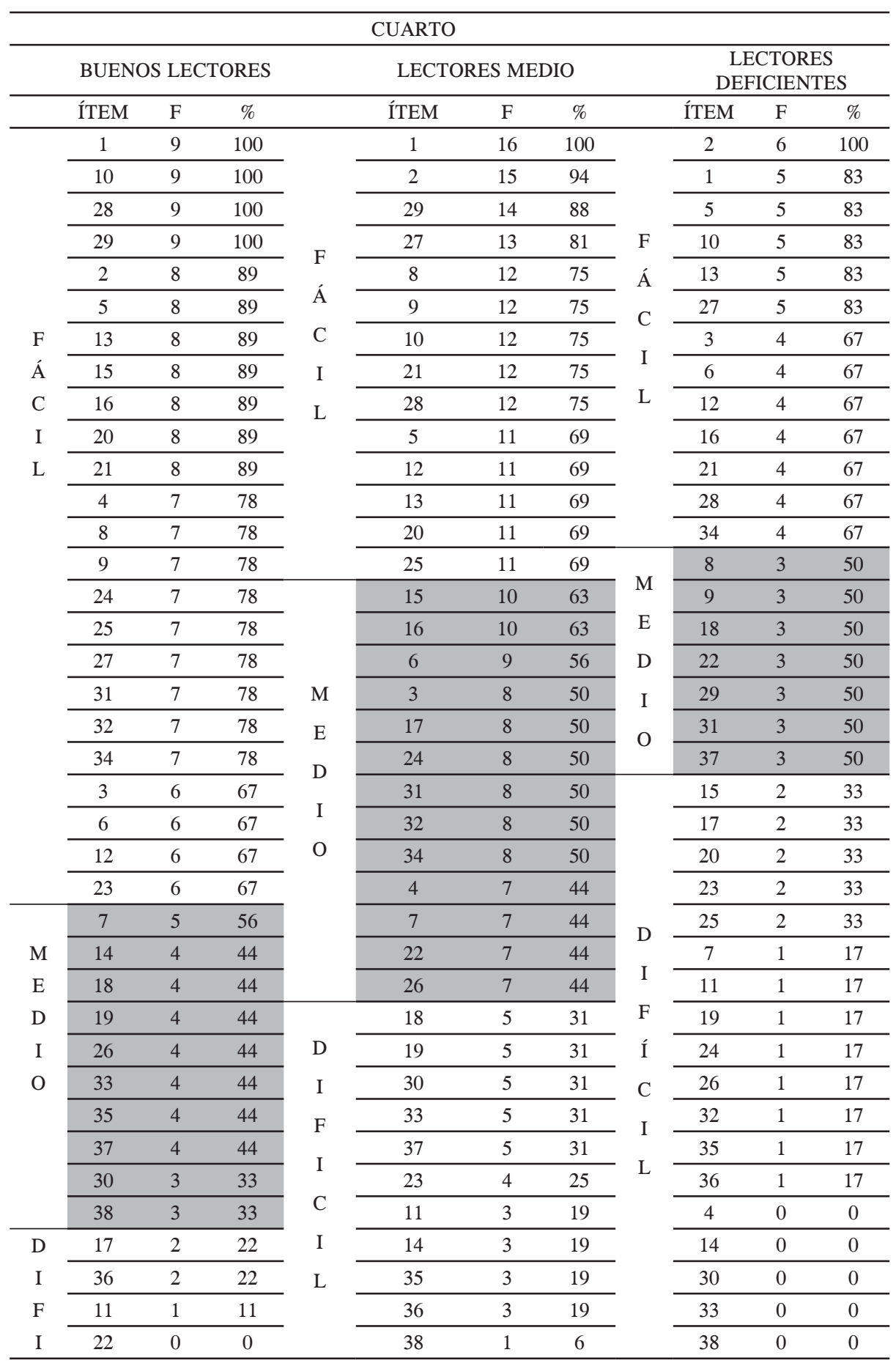


Tabla N. ${ }^{0}$ 5. Porcentaje acumulado de las repuestas correctas de los ítemes de los alumnos buenos lectores, lectores medio y deficientes lectores.

\begin{tabular}{|c|c|c|c|c|c|c|c|c|c|c|c|}
\hline & \multicolumn{7}{|c|}{ QUINTO } & & \multirow{2}{*}{\multicolumn{3}{|c|}{$\begin{array}{c}\text { LECTORES } \\
\text { DEFICIENTES }\end{array}$}} \\
\hline & \multicolumn{3}{|c|}{ BUENOS LECTORES } & & \multicolumn{3}{|c|}{ LECTORES MEDIO } & & & & \\
\hline & ÍTEM & $\mathrm{F}$ & $\%$ & & ÍTEM & $\mathrm{F}$ & $\%$ & & ÍTEM & $\mathrm{F}$ & $\%$ \\
\hline & 2 & 19 & 95 & \multirow{7}{*}{$\begin{array}{l}\mathrm{F} \\
\text { Á }\end{array}$} & 1 & 12 & 100 & \multirow[b]{2}{*}{$\mathrm{F}$} & 2 & 5 & 100 \\
\hline & 21 & 19 & 95 & & 2 & 12 & 100 & & 10 & 5 & 100 \\
\hline & 29 & 19 & 95 & & 21 & 11 & 92 & F́ & 1 & 4 & 80 \\
\hline & 1 & 18 & 90 & & 29 & 11 & 92 & \multirow{4}{*}{$\begin{array}{l}\mathrm{C} \\
\mathrm{I} \\
\mathrm{L}\end{array}$} & 8 & 4 & 80 \\
\hline & 4 & 18 & 90 & & 9 & 10 & 83 & & 13 & 4 & 80 \\
\hline & 9 & 18 & 90 & & 13 & 10 & 83 & & 20 & 4 & 80 \\
\hline $\mathrm{F}$ & 8 & 17 & 85 & & 24 & 10 & 83 & & 33 & 4 & 80 \\
\hline Á & 13 & 17 & 85 & $\mathrm{C}$ & 25 & 10 & 83 & \multirow{18}{*}{$\begin{array}{c}\mathrm{M} \\
\mathrm{E} \\
\mathrm{D} \\
\mathrm{I} \\
\mathrm{O}\end{array}$} & 3 & 3 & 60 \\
\hline $\mathrm{C}$ & 16 & 17 & 85 & I & 27 & 10 & 83 & & 5 & 3 & 60 \\
\hline I & 20 & 17 & 85 & $\mathrm{~L}$ & 28 & 10 & 83 & & 7 & 3 & 60 \\
\hline \multirow[t]{16}{*}{$\mathrm{L}$} & 24 & 17 & 85 & & 3 & 9 & 75 & & 9 & 3 & 60 \\
\hline & 28 & 17 & 85 & & 4 & 9 & 75 & & 15 & 3 & 60 \\
\hline & 32 & 17 & 85 & & 5 & 9 & 75 & & 21 & 3 & 60 \\
\hline & 3 & 16 & 80 & & 10 & 9 & 75 & & 31 & 3 & 60 \\
\hline & 10 & 16 & 80 & & 20 & 9 & 75 & & 34 & 3 & 60 \\
\hline & 12 & 16 & 80 & & 6 & 8 & 67 & & 35 & 3 & 60 \\
\hline & 5 & 15 & 75 & & 7 & 8 & 67 & & 12 & 2 & 40 \\
\hline & 18 & 15 & 75 & & 15 & 8 & 67 & & 16 & 2 & 40 \\
\hline & 23 & 15 & 75 & & 18 & 8 & 67 & & 19 & 2 & 40 \\
\hline & 27 & 15 & 75 & \multirow{9}{*}{$\begin{array}{c}\mathrm{M} \\
\mathrm{E} \\
\mathrm{D} \\
\mathrm{I} \\
\mathrm{O}\end{array}$} & 8 & 7 & 58 & & 22 & 2 & 40 \\
\hline & 37 & 15 & 75 & & 12 & 7 & 58 & & 24 & 2 & 40 \\
\hline & 11 & 14 & 70 & & 17 & 6 & 50 & & 27 & 2 & 40 \\
\hline & 25 & 14 & 70 & & 31 & 6 & 50 & & 30 & 2 & 40 \\
\hline & 34 & 14 & 70 & & 34 & 6 & 50 & & 32 & 2 & 40 \\
\hline & 6 & 13 & 65 & & 35 & 6 & 50 & & 37 & 2 & 40 \\
\hline & 33 & 13 & 65 & & 19 & 5 & 42 & \multirow{13}{*}{$\begin{array}{l}\text { D } \\
\text { I } \\
\text { F } \\
\text { C } \\
\text { I } \\
\text { L }\end{array}$} & 4 & 1 & 20 \\
\hline $\mathrm{M}$ & 15 & 12 & 60 & & 26 & 5 & 42 & & 6 & 1 & 20 \\
\hline $\mathrm{E}$ & 31 & 11 & 55 & & 33 & 5 & 42 & & 14 & 1 & 20 \\
\hline D & 35 & 11 & 55 & & 16 & 4 & 33 & & 17 & 1 & 20 \\
\hline I & 7 & 9 & 45 & & 23 & 4 & 33 & & 25 & 1 & 20 \\
\hline \multirow[t]{4}{*}{$\mathrm{O}$} & 19 & 9 & 45 & D & 11 & 3 & 25 & & 26 & 1 & 20 \\
\hline & 36 & 8 & 40 & I & 14 & 3 & 25 & & 28 & 1 & 20 \\
\hline & 14 & 7 & 35 & $\mathrm{~F}$ & 32 & 3 & 25 & & 29 & 1 & 20 \\
\hline & 17 & 7 & 35 & I & 36 & 3 & 25 & & 11 & 0 & 0 \\
\hline $\mathrm{D}$ & 22 & 6 & 30 & $\mathrm{C}$ & 38 & 2 & 17 & & 18 & 0 & 0 \\
\hline I & 30 & 3 & 15 & I & 37 & 1 & 8 & & 23 & 0 & 0 \\
\hline $\mathrm{F}$ & 26 & 2 & 10 & $\mathrm{~L}$ & 22 & 0 & 0 & & 36 & 0 & 0 \\
\hline I & 38 & 2 & 10 & & 30 & 0 & 0 & & 38 & 0 & 0 \\
\hline
\end{tabular}

3. Teniendo como referencia los datos de las tablas de porcentaje acumulado de la frecuencia de respuestas correctas, se ha identificado los ítemes difíciles y de dificultad media de acuerdo a las operaciones del pensamiento sólo para los alumnos buenos y deficientes 
lectores en cada grado, distribuidos en la Tabla N. ${ }^{\circ} 6$ los que son expresados en términos de porcentajes en la Tabla N. ${ }^{\circ} 7$.

Tabla N. ${ }^{0}$ 6. Distribución de los ítems difíciles y de dificultad media por categoría de operaciones del pensamiento de los alumnos deficientes y buenos lectores de segundo a quinto grado.

\begin{tabular}{|c|c|c|c|c|c|}
\hline \multirow{2}{*}{$\begin{array}{l}\text { Operaciones del } \\
\text { pensamiento }\end{array}$} & \multirow{2}{*}{ Grados } & \multicolumn{2}{|c|}{ Lectores deficientes } & \multicolumn{2}{|c|}{ Buenos lectores } \\
\hline & & Ítemes difíciles & $\begin{array}{l}\text { Ítemes dific. } \\
\text { media }\end{array}$ & Ítems difíciles & $\begin{array}{l}\text { Ítems dif. } \\
\text { media }\end{array}$ \\
\hline \multirow{4}{*}{ Clasificación } & 2do grado & $15,24,30$ & 5,20 & 30 & - \\
\hline & 3er grado & $15,27,30$ & $13,20,24$ & 15,30 & 13,27 \\
\hline & 4to grado & $15,20,24,30$ & --- & 30 & 15,24 \\
\hline & 5to grado & ----- - & $5,15,24,27,30$ & 30 & 15 \\
\hline \multirow{7}{*}{ Análisis-Síntesis } & 2do grado & $4,7,11,, 14,21$ & $3,6,8,9,28$ & 7 & $6,11,14,22,23$ \\
\hline & & $22,23,26,33$ & & & 26,33 \\
\hline & 3er grado & $3,4,6,8,11,14,22$ & $7,9,21$ & $7,8,11$ & $3,4,6,22,33$ \\
\hline & & $23,26,28,33$ & & 14,26 & \\
\hline & 4to grado & $4,7,11,14,23,26$ & $8,9,22$ & 11,22 & $7,14,26,33$ \\
\hline & & 33 & & & \\
\hline & 5to grado & $\begin{array}{l}4,6,11,14,23,26 \\
28\end{array}$ & $\begin{array}{l}3,7,9,21, \\
22\end{array}$ & $\begin{array}{l}22,26 \\
3\end{array}$ & $6,7,14,3$ \\
\hline \multirow{6}{*}{ Inferencia lógica } & 2do grado & $12,19,25,29,31$ & $10,16,32$ & $36,37,38$ & $19,31,32$ \\
\hline & & $34,36,37,38$ & & & \\
\hline & 3er grado & $\begin{array}{l}12,34,36,37,38 \\
1,32\end{array}$ & $19,25,29,3$ & $12,19,36,38$ & 16,37 \\
\hline & 4to grado & & & 36,38 & 19,37 \\
\hline & & $19,25,32,36,38$ & $29,31,37$ & & $19,31,36$ \\
\hline & 5to grado & $\begin{array}{l}25,29,36,38 \\
12,16,19,31,32,37\end{array}$ & & & \\
\hline \multirow{4}{*}{$\begin{array}{l}\text { Razonamiento } \\
\text { hipotético }\end{array}$} & 2do grado & $17, \mathbf{1 8}, \mathbf{3 5}$ & $17,18,35$ & ---- & $17,18,35$ \\
\hline & 3er grado & $17,18,35$ & ---- & ----- & 17,35 \\
\hline & 4to grado & 17,35 & 18 & 17 & 18,35 \\
\hline & 5to grado & 17,18 & 35 & ---- & 17,35 \\
\hline
\end{tabular}


Tabla N. ${ }^{0}$ 7. Porcentaje de ítemes difíciles y de dificultad media por operaciones del pensamiento de los deficientes y buenos lectores en cada grado educativo.

\begin{tabular}{|c|c|c|c|c|c|c|c|c|c|}
\hline \multirow[t]{2}{*}{ OPERACIONES } & \multirow[t]{2}{*}{ SUJETOS } & \multicolumn{2}{|c|}{ SEGUNDO \% } & \multicolumn{2}{|c|}{ TERCERO \% } & \multicolumn{2}{|c|}{ CUARTO \% } & \multicolumn{2}{|c|}{ QUINTO \% } \\
\hline & & ID + IM & Fácil & ID+ IM & Fácil & ID+IM & Fácil & ID + IM & Fácil \\
\hline \multirow{2}{*}{ Clasificación } & Defic. lectores & 56 & 44 & 67 & 33 & 44 & 56 & 56 & 44 \\
\hline & Buenos lectores & 11 & 89 & 44 & 56 & 33 & 67 & 22 & 78 \\
\hline \multirow{2}{*}{ Análisis - síntesis } & Defic. lectores & 100 & 0 & 100 & .0 & 64 & 36 & 86 & 14 \\
\hline & Buenos lectores & 57 & 43 & 71 & 29 & 43 & 57 & 43 & 57 \\
\hline \multirow{2}{*}{ Inferencia lógica } & Defic.lectores & 100 & 0 & 83 & 17 & 67 & 33 & 83 & 17 \\
\hline & Buenos lectores & 50 & 50 & 50 & 50 & 33 & 67 & 33 & 67 \\
\hline \multirow{2}{*}{$\begin{array}{l}\text { Razonamiento } \\
\text { hipotético }\end{array}$} & Defic. lectores & 100 & 0 & 100 & 0 & 100 & 0 & 100 & 0 \\
\hline & Buenos lectores & 100 & 0 & 67 & 33 & 100 & 0 & 67 & 33 \\
\hline
\end{tabular}

En la Tabla N. ${ }^{\circ} 6$ se pudo observar que, en todas las categorías de operaciones, a excepción de razonamiento hipotético, existe un predominio de ítemes difíciles y de dificultad media en los alumnos deficientes lectores en relación a los buenos lectores. Lo cual se confirma por los porcentajes que se muestran en la Tabla N. ${ }^{0} 7$.

En razonamiento hipotético, se observa los mismos ítemes en los dos grupos; la diferencia estriba que son difíciles en los deficientes lectores de dificultad media en los buenos lectores.

Un análisis por categoría de operación del pensamiento nos permite apreciar el rendimiento diferencial de cada grupo de alumnos.

\section{Clasificación}

Los lectores deficientes evidencian consistentemente dificultades en determinados ítemes: 15, 20, 24 y 30 en todos los grados; el ítem 5, en segundo y tercero; el ítem 20 en segundo, tercero y cuarto; el 27, en segundo y quinto. Los buenos lectores presentan dificultades en los ítemes 30 en todos los grados, dificultad media en los ítemes 13 y 27 sólo en segundo y en el ítem 15, en segundo y dificultad media en cuarto y quinto grados.

Interpretando estos resultados, en términos de las funciones cognitivas deficientes que subyacen a los ítemes y a los aspectos psicolingüísticos, las mayores dificultades que presentan los deficientes lectores en la operación de clasificación se dan: 
- A nivel de proposiciones (microestructura), en el que influye la organización del contenido (superestructura), los ítemes relacionados con el significado de palabras (5), identificación de la idea explícita en el texto $(13,15,24,27)$ las funciones cognitivas deficientes estarían vinculadas con: vocabulario, comportamiento sistemático, precisión y exactitud, y comparación espontánea.

- A nivel del significado global del texto (macroestructura): Vocabulario (ítemes 20, 24 y 30) compartiendo además, las mismas funciones señaladas en el nivel de la microestructura, a lo que se añade, la búsqueda de dos o más fuentes de información. Es igualmente importante el nivel de superestructura u organización del contenido.

Los ítemes consistentemente más difíciles en los deficientes y buenos lectores son 15 y 30 . Ambos requieren comportamiento sistemático, precisión y exactitud; el primero incluye además, comparación espontánea y el segundo, dos o más fuentes de información.

Tanto a nivel de micro y macroestructura, los ítems difíciles y de dificultad media que comparten los deficientes y buenos lectores son de mayor abstracción y complejidad.

Los porcentajes que representan los ítemes difíciles y de dificultad media totalizados de la tabla N. ${ }^{\circ} 7$ presentan valores entre 44 y $67 \%$ en los deficientes lectores y de tendencia moderada en los buenos lectores.

\section{Análisis - Síntesis}

En este binomio de operaciones del pensamiento, específicamente la síntesis, existe un mayor predominio de ítemes difíciles y menos de dificultad media en los deficientes lectores, sucediendo lo contrario en los buenos lectores: los ítemes de dificultad media prevalecen sobre los ítemes difíciles en todos los grados. A juzgar por los porcentajes acumulados de ítemes difíciles y de dificultad media (entre 67 y 100\%), la síntesis es el proceso que evidencia mayor dificultad tanto en los alumnos deficientes lectores como en los buenos lectores en quienes la tendencia es moderada en cuarto y quinto, y moderada con tendencia a alta en segundo y tercero (porcentajes entre $53 \%$ a $71 \%$ ).

En términos generales, la síntesis como operación del pensamiento se relaciona fundamentalmente con la función sumativa y la visión global que se va formando el lector del texto. Cuando el sujeto tiene que extraer la idea principal, tanto de las proposiciones (microestructuras) como del texto en su conjunto (macroproposición), el proceso básico es el de resumir, al distinguir los aspectos relevantes de los irrelevantes, cuando tiene que poner un título (ítemes 3, 8,11, 26,33), ordenar las ideas principales (ítemes 4 , 7 ), identificar lo que versa el texto, es decir tener una idea global del mismo (ítemes 6 , $9,12,14,21,22,23,28)$.

Los ítemes o preguntas de mayor dificultad, tanto para los deficientes como para los buenos lectores, son: 26 y 33, por la mayor complejidad en las relaciones de jerarquía de las ideas globales del texto. 


\section{Inferencia lógica}

En esta operación del pensamiento, los deficientes lectores evidencian dificultad en una gran proporción de ítemes en todos los grados, especialmente en segundo; presentan igualmente ítemes de dificultad media, aunque en menor proporción. Los buenos lectores tienen dificultad media en un numero considerable de ítemes revelando en segundo y tercer grado mayor dificultad (ver Tabla N. ${ }^{\circ} 6$ ).

Los valores cuantitativos de la Tabla N. ${ }^{\circ} 7$ muestran objetivamente los niveles de desempeño de los deficientes y buenos lectores: los primeros oscilan entre un porcentaje de $67 \%$ en cuarto grado a $100 \%$ en el segundo grado. Los buenos lectores varían entre $33 \%$ en quinto a $50 \%$, en segundo.

Las inferencias que deben realizar los alumnos como demanda cognitiva del texto se derivan de la idea global que se supone los alumnos van adquiriendo de la lectura a través del texto, es decir, de las microestructuras (preguntas 10,12,16,19) en las que subyace un conjunto de funciones básicas: relaciones temporales, comportamiento sistemático, uso de varias fuentes de información, percepción global, elaboración de categorías cognitivas, conducta sumativa, respuestas claras y precisas, a lo que se añade la influencia de los aprendizajes previos (culturales, científicos, sociales) cuyos contenidos requieren mayor procesamiento (ítemes 25, 29, 31, 32, 34, 36, 37,38).

Preguntas como la 19 y 37 son igualmente difíciles en los deficientes como buenos lectores en todos los grados (excepto la 37 en quinto grado) en el que la deducción se tiene que realizar entre las relaciones que se establecen entre contenidos más complejos.

\section{Razonamiento hipotético}

En este proceso, estrechamente vinculado a la inferencia lógica, se ha identificado solamente tres ítemes $(17,18,35)$ cuya demanda cognitiva de resolución, exige plantear una hipótesis. Las preguntas formuladas en el Test parten de supuestos para ser verificados en términos de razonamiento hipotético derivados de las ideas globales del texto influyendo sobremanera en la respuesta, el conocimiento de los contenidos culturales.

En términos generales, los ítemes son difíciles en los deficientes lectores y de dificultad media en los buenos lectores. Los porcentajes entre ítemes difíciles y de dificultad media corresponde al $100 \%$ de los deficientes lectores de todos los grados. Los buenos lectores oscilan entre $100 \%$ en segundo y cuarto y $67 \%$ en tercero y quinto grados.

La explicación de las dificultades que presentan tanto los buenos y deficientes lectores en este proceso gira en torno a las siguientes causas: la mayor complejidad y abstracción de los contenidos, el que la respuesta se derive tanto de la idea global que se forma el lector de las relaciones entre las proposiciones, como el tener que considerar varias fuentes de información, percibir y definir el problema con claridad, y comunicación descentralizada (no egocéntrica). 


\section{DISCUSIÓN}

La lectura, como aspecto del lenguaje, comparte la característica de constituir una herramienta del pensamiento, lo que implica razonamiento de orden superior propio del ser humano. Los sistemas lenguaje y pensamiento, complejos y diferenciados se encuentran estrechamente vinculados por la comunicación a través de una lengua. Al abordarla, a través de los procesos cognitivos, debe producirse la comprensión en una de sus manifestaciones más complejas que es la lectura.

En el presente estudio hemos tratado de identificar los procesos cognitivos básicos, en términos de operaciones y funciones mentales que subyacen en el desempeño lector, relacionándolas con los niveles de procesamiento textual, y que permitan explicar las diferencias que existen entre los deficientes y buenos lectores

Una visión de conjunto de los resultados analizados de cada uno de las operaciones del pensamiento, nos permite apreciar algunos datos de interés tanto teóricos como prácticos que revelan algunas tendencias, que más que conclusiones, representan reflexiones sobre los procesos de la lectura y sus implicaciones pedagógicas.

En primer lugar, las operaciones del pensamiento que explican las diferencias entre los deficientes y buenos lectores, son análisis-síntesis e inferencia lógica. Sin embargo, se observa que los buenos lectores tienen dificultades en ambos procesos aunque en menor proporción.

Tanto a nivel de micro y macroestructura, los ítems difíciles y de dificultad media que comparten los deficientes y buenos lectores son de mayor abstracción y complejidad no solo por las operaciones implicadas sino por el contenido cultural y académico de los párrafos del test (superestructura y modelo de la situación). Esta observación es también válida para el razonamiento hipotético, proceso cognitivo en el que tanto los buenos como deficientes lectores presentan relativamente mayores dificultades.

Respecto a la operación de clasificación, base para la conceptualización, son evidentes las dificultades en los deficientes lectores, especialmente en tercer grado, aunque en menor proporción que en las demás operaciones del pensamiento. En los buenos lectores, los porcentajes acumulados de dificultad de los ítemes son menores en segundo y quinto grados, y moderados en tercero y cuarto (44\% y $33 \%)$.

Un hecho que no debemos pasar por alto es el carácter dinámico de los procesos cognitivos. El análisis realizado ha sido en función de la demanda cognitiva del planteamiento de las preguntas de la prueba; sin embargo, en el proceso de identificación de la respuesta correcta están implicadas las operaciones y funciones cognitivas y la competencia lingüística que se entretejen y se activan casi simultáneamente.

Asimismo, no debemos perder de vista que "no hay un modo diferente en que los malos lectores obtienen sentido de un texto, cuando se les compara con los buenos lectores. La diferencia reside en lo bien que cada lector utiliza este único proceso de la lectura" (Goodman, 1982).

En relación a las funciones, base de las operaciones mentales, y de las que adolecen los lectores deficientes y de alguna medida los buenos lectores, estarían afectando el procesamiento de la información de la lectura en las diferentes fases del proceso, siendo las principales: 


\section{En la fase de entrada}

- Conocimiento confuso, superficial de los datos que proporciona una determinada fuente de información.

- Comportamiento no planificado e impulsivo, que se caracteriza en la búsqueda desordenada y asistemática de la información, y que afecta las fases de elaboración y comunicación de la respuesta.

- $\quad$ Carencia de instrumentos verbales o ausencia de códigos verbales no solo en la fase de entrada sino en las de elaboración y comunicación, por la carencia de términos y conceptos que no permiten la generalización a partir de las experiencias concretas.

- $\quad$ En la dimensión temporal, en la medida que representan la posibilidad de trascender la situación inmediata y permitir describir la forma en que objetos, personas, hechos y situaciones se relacionan entre sí, en términos de secuencia y proximidad en el tiempo.

- Imprecisión e inexactitud en la recolección de datos.

- $\quad$ Dificultad en el manejo de relaciones que deben establecerse entre dos o más fuentes de información.

\section{En la fase de elaboración}

- Dificultad de definir una situación problemática y unido a ello, insuficiencia para distinguir datos relevantes de los irrelevantes.

- Estrechez de campo mental que dificulta la flexibilidad, que es la capacidad para utilizar diferentes fuentes de información, estableciendo entre ellas una coordinación y una serie de combinaciones validas para llegar al pensamiento abstracto y productivo.

- Insuficiencia de la conducta comparativa, base del proceso de relaciones que se establecen en la mente.

- Insuficiencia en la visión global, no episódica de la realidad, caracterizada por posturas generales y vagas, cargadas de imprecisiones e interpretaciones muy concretas, debido a la limitada ejercitación de la conducta hipotética y sumativa.

- Limitaciones en la elaboración de categorías cognitivas vinculadas al vocabulario deficiente.

\section{En la fase de de salida}

- Comunicación egocéntrica, no descentralizada.

- Bloqueo en la comunicación de respuestas por la carencia de instrumentos verbales adecuados y precisión y exactitud de la expresión

- Conducta impulsiva 


\section{CONCLUSIONES}

Constituyendo este estudio un intento de caracterización cualitativa de las deficiencias de la lectura de nuestros estudiantes, un sustento práctico a nuestros resultados lo encontramos en el estudio realizado por ESAN (2005) de la capacitación docente entre los años 1999 al 2003 a nivel nacional. Entre otros aspectos, la comprensión lectora fue parte del proceso de evaluación académica del área de Comunicación ${ }^{1}$ realizada en una muestra de 2049 1912 estudiantes de cuarto y quinto de Secundaria, respectivamente.

Entre los resultados relevantes para nuestro estudio, en Cuarto grado de secundaria se observó que el acierto de las preguntas, planteadas en esta área, alcanza los mayores niveles en las preguntas referidas a la adecuación y corrección gramatical y al uso correcto de conectores; mientras que las mayores debilidades se encuentran en algunos aspectos de la comprensión de lectura, principalmente en aquellos en los que se requiere del alumno, un esfuerzo de síntesis, como la definición del título adecuado a un texto.

Comparando las instituciones educativas en función a su pertenencia a la zona urbana o rural, el rendimiento de los alumnos de IE de zonas urbanas es ampliamente superior a los de las zonas rurales.

Cuando se profundiza la información, se puede apreciar que son las zonas urbanas las que presentan un rendimiento mejor en Comunicación en todas las zonas del país, en especial en la sierra y en la selva, que incluso alcanzan niveles que superan Lima Metropolitana y Callao y Costa Urbana. El rendimiento más bajo se aprecia en la zona costa rural.

En la misma dirección se aprecian los resultados en Quinto grado, tanto en lo que respecta al rendimiento diferencial por zonas, a favor de las urbanas sobre las rurales y de las zonas sierra urbana y selva urbana sobre Lima Metropolitana y Callao y Costa urbana; y el nivel de acierto de las respuestas observadas en Cuarto Grado: mayores niveles en las preguntas de adecuación y corrección gramatical, y mínimo en las preguntas que implican un esfuerzo de síntesis.

Las implicaciones pedagógicas del estudio tienen gran relevancia en la medida que los resultados permitirán una mejor elaboración de las preguntas de las pruebas de evaluación, por un lado, y por otro, una mejor comprensión de los procesos cognitivos que subyacen en la comprensión de la lectura para darles un mayor énfasis en el proceso didáctico.

1 Los aspectos evaluados en el área de Comunicación, además de la comprensión e interpretación de textos, fueron la estructuración gramatical de una oración y el uso correcto de conectores. 


\section{REFERENCIAS BIBLIOGRÁFICAS}

1. Burón, J. (1999). Enseñar a aprender. Introducción a la metacognición. España: Edit. Mensajero.

2. Cassany, D.(2004). "Explorando las necesidades actuales de comprensión. Aproximación a la comprensión crítica”. En Lectura y vida. Año 25, N. ${ }^{\circ} 2$.

3. Condemarín, M. (2001). "Estrategias de enseñanza para activar esquemas cognitivos de los estudiantes". En Lectura y vida. Año 21, N. ${ }^{\circ} 2$.

4. Corral, I. (1986). El funcionamiento cognoscitivo del adulto. España: Estudios de Educación a Distancia. UNED.

5. Feuerstein, R. (1997). "Teoría de la Modificabilidad Cognitiva Estructural”. En: ¿ Es Modificable la inteligencia? Congreso de la AEMC de Madrid, 1995. Seminario de Utrecht,1996. Seminario de París de 1996. España: Edit. Bruño.

6. Gil, A., Riggs, E.,Cañizales,R. (2001). "Metacognición: punto de ignición del lector estratégico”. Lectura y vida. Año 22, N. ${ }^{0} 3$.

7. González,R. (1998). Comprensión lectora en estudiantes universitarios iniciales. Persona.Revista de Psicología. Universidad de Lima.

8. González, R. (2001). "El papel del componente superestructural en la elaboración de las macroestructuras". En Persona, Revista de la Facultad de Psicología. Lima: Universidad de Lima

9. González, E. (2003). "Desarrollo de habilidades de pensamiento en el aula". Taller de Didáctica de la Lógica, Conferencia UNAM. México: Universidad Nacional Autónoma de México.

10. Goodman, K (1982). "El proceso de lectura: Consideraciones a través de las lenguas y del desarrollo". En: Ferreyros, E. y Gómez, M. (Comp.). Nuevas perspectivas sobe los procesos de lectura y escritura. Edit. Siglo XXI.

11. Higueras, L. (1998).Aprendiendo a pensar. Lima: Publicaciones COPH.

12. Kaufman, A.M., Perelman F. (1999). "El resumen en el ámbito escolar”. En: Lectura $y$ vida Año 20, N. ${ }^{\circ} 4$.

13. León, J. (1999). Pensamiento y educación: Un enfoque cognitivo. Buenos Aires: Aiqué.

14. Morles, A.;Amat, M., Denis, Y.,Urquhart, R. (1997). "Resolución de problemas de procesamiento de la información directa en la lectura”. En: Lectura y vida Año $18, N{ }^{\circ} 3$.

15. Pilonieta,P. (1997). "Los procesos de desarrollo de la inteligencia en el marco de la teoría de la modificabilidad estructural cognitiva”. Congreso sobre Estrategias para el desarrollo intelectual. Colombia.

16. Rinaudo,M.C., González, A. (2002). "Estrategias de aprendizaje, comprensión de la lectura y rendimiento académico". En Lectura y vida, Año 23, N. ${ }^{\circ} 3$. 
17. Sánchez, E. (1999). "El lenguaje escrito: Adquisición e intervención educativa". En: Psicología de la instrucción I variables y procesos básicos. España: Edit. Síntesis.

18. Sternberg, L., Spear-Swerling, L. (1999). Enseñar a pensar. Aula XXI. Edit. Santillana.

19. Solé (1996). "Estrategias de comprensión de la lectura". En: Lectura y vida Año 17, N. ${ }^{\circ} 4$,

20. Taboada, A. y Guthrie, J. (2005). "La lectura en materias de contenido. Lo que sabemos y lo que necesitamos saber”. En: Lectura y vida Año Año 26, N. ${ }^{\circ} 1$.

21. Tapia,V. (1999). "Efectos de un programa de estrategias cognitivas y metacogntivas para mejorar la comprensión lectora". En Revista de Psicología Año III. No 4. Lima: Facultad de Psicología, Universidad Nacional Mayor de San Marcos.

22. Tapia,V. ( 2003). Programa Psicopedagógico de Comprensión Lectora: Aprendo a pensar a través de la lectura. Lima: Facultad de Psicología, Universidad Nacional Mayor de San Marcos.

23. De Vega, M., Carreras, M., Gutiérrez-Calvo, Alonso-Quecuty, M. (1990). Lectura y Comprensión.Una perspectiva cognitiva. Madrid: Alianza Editorial S.A. 